\title{
Association of rs2231142 with Serum Uric Acid among the Nepalese Patient Visiting the Tertiary Care Hospital
}

\section{Lama BT, Roka Pun HT, Parajuli AT, Tamang RT, Deshar NK, Banstola SR and Koirala N* \\ Department of Medical Biochemistry, Nobel College, Pokhara University, Nepal}

*Corresponding author: Dr. Niranjan Koirala, Head of the Department,

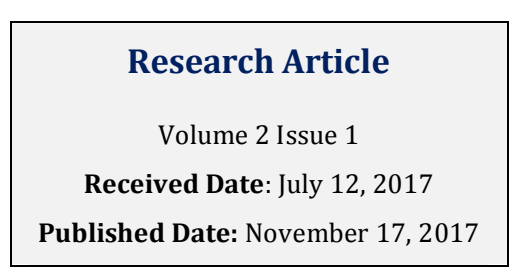

Department of Medical Biochemistry, Nobel College of Health Sciences, Pokhara University, Sinamangal, Kathmandu, Nepal, Tel: +977 1 4110525; Fax: +977 1 4110880; Email: koirala.biochem@gmail.com

IThese authors contributed equally to this work

\section{Abstract}

Background: Uric acid is the byproduct of purine nucleotide catabolism. Hyperuricemia is an excess of uric acid in the blood which leads to gout. The single nucleotide polymorphism, C-to-A mutation rs223114 in ABCG2 gene, that results in a Q-to-K substitution at position 141, has been associated with hyperuricemia and gout. However, this association, in Nepalese patient, has not been established.

Objectives: To examine the association of SNP rs2231142 in ABCG2 gene with serum uric acid in Nepalese people for the 1 st time.

Methods: A total of 30 samples with elevated serum uric acid were genotyped for rs2231142 and association of this variant with uric acid was investigated.

Results: Among 30 samples, 40\% of the patients tested positive for rs 2231142 mutation and remaining $60 \%$ of the patient tested negative for the mutation. Both type of mutation (i.e. homozygous as well as heterozygous mutation) were found in which mainly heterozygous mutation was found to be predominant (30\%).

Conclusions: This study concluded the positive association of the rs2231142 variant of ABCG2 gene with serum uric acid in Nepalese population where heterozygous mutation was more prevalent.

Keywords: Uric acid; Hyperuricemia; Gout; ABCG2; SNP; rs2231142

\section{Introduction}

In humans, metabolic product of purine is known as uric acid, whose levels are primarily determined by endogenous metabolism like synthesis and cell turn over, rate of reabsorption and excretion through the kidney [1]. The metabolism of dietary and endogenous nucleic acids produces purines which are ultimately degraded to uric acid in man, through the action of the enzyme xanthine oxidase [2]. Serum uric acid concentration within the population has a Gaussian distribution, with a typical reference range of 120-420 $\mu \mathrm{mol} / \mathrm{L}$ [3]. Elevation in the serum uric acid concentration is known as hyperuricemia [4]. Monosodium urate crystals get deposited in joints due to the elevation of serum uric acid leading to a clinical syndrome called gout [5]. The majority of hyperuricemia and gout are due to the defect in renal 


\section{International Journal of Biochemistry \& Physiology}

excretion of urate [1]. Remarkably, in human, high serum uric acid concentration is also linked with different disorders like cardiovascular [6], diabetes and kidney diseases [7], metabolic syndrome [8] and one of the most usual form of arthritis [9]. Sometimes human lifestyles like excess alcohol consumption is also believed to increase the serum uric acid [9]

Besides environmental factor, serum uric acid concentration is also genetically regulated. The $\mathrm{G} \mu \mathrm{l}$ family $\mathrm{ABC}$ transporter, $\mathrm{ABCG} 2$ protein is a highcapacity transporter for uric acid excretion in the kidney, liver, and gut $[10,11]$. ABCG2 single nucleotide polymorphism is interlinked with various phenotypes, including UA levels, gout, and low-density lipoproteins level [10]. The C-to-A mutation rs2231142, resulting in a Q-to-K substitution at position 141, causes reduction of urate transport activity by $53 \%$ which is responsible for hyperuricemia and gout. Hence, hyperuricemia is more likely to develop in people carrying the rs2231142 [10]. Both environmental and genetic factor influence on serum uric acid concentration with heritability estimates of up to $73 \%$ [12].

As per the past studies, male have stronger association between rs2231142 and uric acid than female suggesting sex modifies the association [13], however, the study conducted by Anita showed an inconsistency in this evidence [14]. The $A B C G 2$ protein mediates the renal urate secretion as a urate efflux transporter in the (luminal) brush-border membrane of kidney proximal tubule cells [13]. According to recent evidence, before degradation, a significant portion of mutant $\mathrm{Q} 141 \mathrm{~K}$ protein accumulate in perinuclear aggresomes and after proteasomal degradation there may be partial decrease in protein expression and function. Hence, the loss of urate transport function for Q141K was specifically due to the reduction in protein expression [15].

Epidemiological studies have revealed that the prevalence and incidence of gout are increasing relatively being more prevalent in Asia regions $[16,17]$. The study conducted by S Kumar concluded that the prevalence of patients with hyperuricemia was $21.42 \%$ in Chitwan district of Nepal and that in Lumbini was $17.38 \%[18,19]$. The previous studies have shown the association between SNP rs2231142 and increased serum uric acid and gout in American, Asian, Taiwanese, Japanese, Korean, Chinese Han population, German, and New Zealand Pacific Island ancestry [10,13,20-25]. Lastly, the association of SNP rs2231142 with hyperuricemia has not been established in Nepalese population. Therefore, we conducted a study to find out the association of SNP rs2231142 mutation with increased serum uric acid in Nepalese patients.

\section{Materials and Methods}

\section{Study population}

Clinically diagnosed hyperuricemic patients were taken for sampling.

\section{Inclusion criteria}

- Individual should be Nepalese hyperuricemic patient.

\section{Exclusion criteria}

- Individual with normal serum uric acid level.

- Individual with kidney disease.

Study Design: This is a prospective type of study.

Study setting: The research was conducted in Decode Genomics and Research Center, Sinamangal, Kathmandu, Nepal.

Study Period: This study was conducted from August to October of 2016.

Sample Size: 30 samples were taken for this study.

\section{Approval of the study}

Ethical approval for the study protocol was obtained from the Nobel College Institutional Research Council approved by National Health Research Council (NHRC), and written consent was taken from all patients.

\section{DNA extraction and genotyping}

DNA was extracted using Spinstar TM Total DNA kit. The basic steps of DNA isolation are disruption of the cellular structure to create a lysate, separate the soluble DNA from cell debris and other insoluble material and purify the DNA of interest from soluble proteins and other nucleic acids. Extracted DNA was electrophoresed on 1\% agarose gel for assessing the intactness of DNA. The reaction and the PCR program were standardized to precisely amplify the rs2231142 in ABCG2 gene in the DNA sample at annealing temperature $57^{\circ} \mathrm{C}$ with reaction mixture of $25 \mu \mathrm{l}$ using outer primer double than the inner $(0.5 \mu \mathrm{l})$. Primers rs2231142 forward outer and reverse outer primer amplifies a 482 bp fragment, Primer rs2231142 reverse inner and forward outer primer amplifies a 328 bp fragment from wild type allele and Primer rs2231142 forward inner and reverse outer primer amplifies a $199 \mathrm{bp}$ fragment from mutant type allele only in the presence of Q141K mutation in ABCG2 gene. PCR amplified products were run on $2 \%$ agarose gel prepared with $1 \mu \mathrm{g} / \mathrm{ml}$ of Ethidium Bromide and the DNA bands were observed under UV transilluminator. 


\section{International Journal of Biochemistry \& Physiology}

\section{Results}

In the sample of 30 hyperuricemic patients (serum uric acid $>7 \mathrm{mg} / \mathrm{dl}$ ) of varying ages, $18(60 \%)$ were male, $12(40 \%)$ were female and their genotyping were done to determine the association of rs2231142 with hyperuricemia and to calculate the percentage of heterozygous and homozygous mutation. After extraction of DNA from the whole blood with the use of DNA extraction kit, it was allowed to run in $2 \%$ of agarose gel electrophoresis. Then it was subjected to the AS PCR which showed band of different sizes.

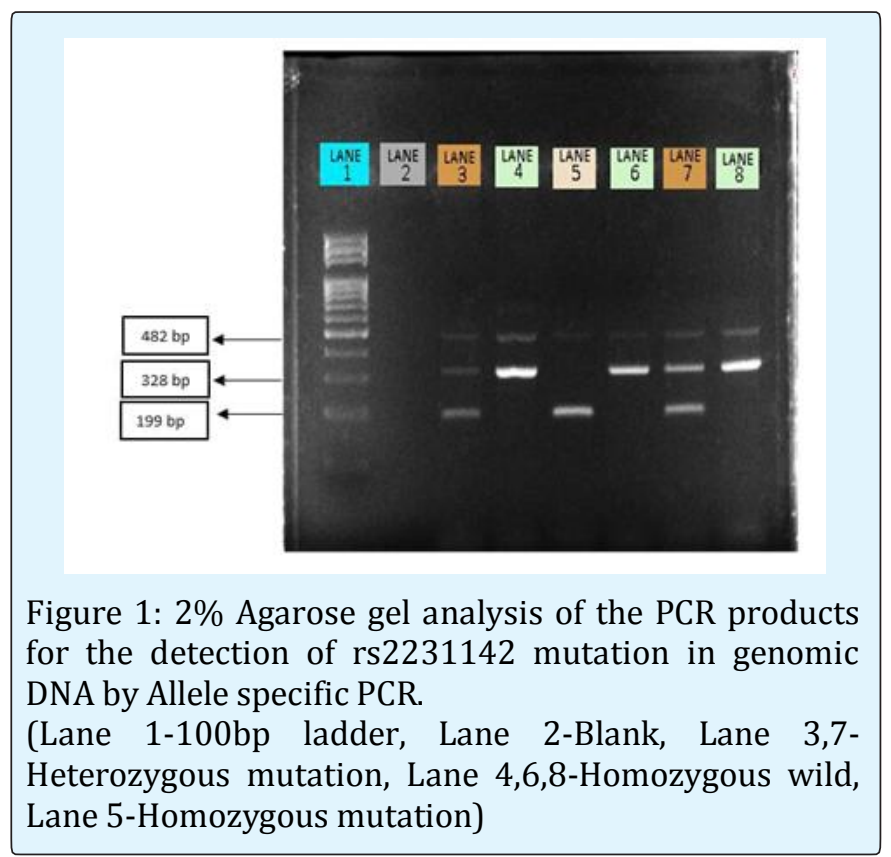

\section{Detection of rs2231142 Mutation}

Using AS-PCR as diagnostic method, $60 \%$ of the test samples did not have rs 2231142 mutation and $40 \%$ of the test samples were declared to contain mutation. This mutation includes both type of mutation i.e. heterozygous as well as homozygous mutation.

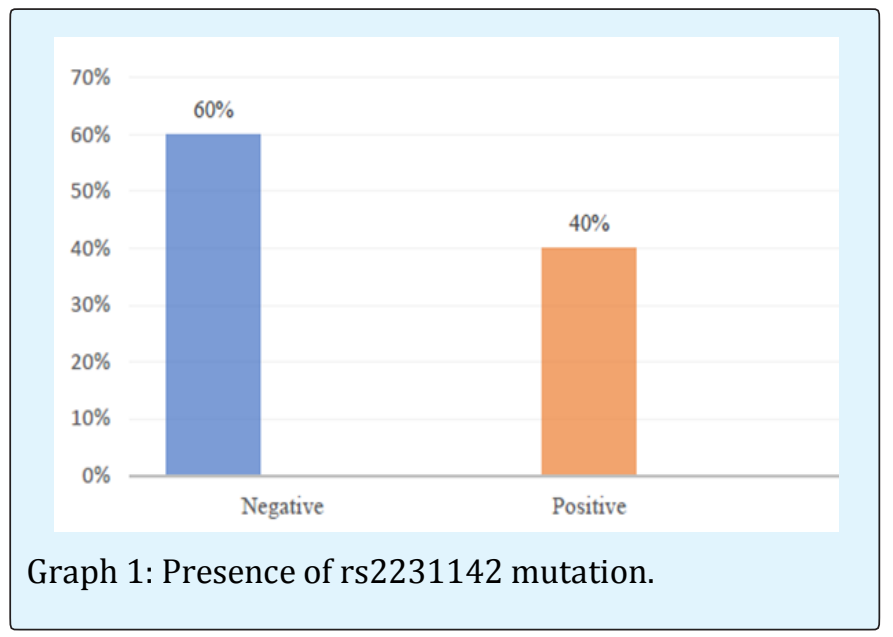

Among 30 hyperuricemic patients observed, 30\% of the patients were declared to contain rs2231142 heterozygous mutation, $10 \%$ contain rs2231142 homozygous mutation. So, $60 \%$ of the test samples were successfully declared to be void of rs2231142 mutation.

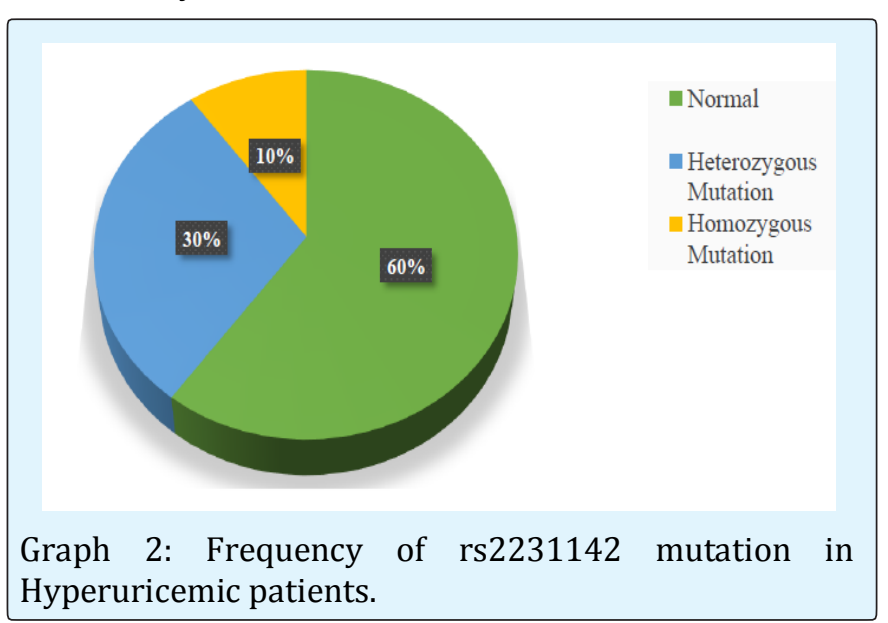

\section{Discussion}

This study was carried in the 30 patients with high serum uric acid and showed that there is the association between rs2231142 with serum uric acid in Nepalese population agreeing with the result found by the other studies done in China, Japan and other European countries [10,26,27].

This study successfully operated and implemented AS-PCR to analyze the 30 samples of the patients with high serum uric acid value. Among which $40 \%$ of the patient tested positive for rs2231142 mutation and remaining $60 \%$ of the patient tested negative for the mutation. Both type of mutation (i.e. homozygous as well as heterozygous mutation) were found in which mainly heterozygous mutation was found to be predominant (30\%). The $40 \%$ positive result suggests that there is the presence of association between rs2231142 and serum uric acid in Nepalese population as well.

The study done by Yang B et.al shows that the missense SNP rs2231142 in ABCG2 have strongest association with serum UA level. Thus, this missense SNP could result in a glutamine-to-lysine amino acid substitution and the glutamine residue is highly conserved across species and the LD pattern differs in Chinese population and European population. This study also agrees the association of SNP rs2231142 with serum UA level with this conclusion [28].

According to our best knowledge, this is the first time the study on association between rs2231142 and uric acid has been carried out in Nepal. The sample size of 


\section{International Journal of Biochemistry \& Physiology}

this study is small due to which we are unable to detect the association of this SNP on the basis of many factors. This study limits to the patient with high serum uric acid. We have not gone through the patient medical history. However, this study does not include the sample of the patient having the kidney disease. For confirmation of the prevalence of mutation of rs2231142 further studies should be done with larger number of population from various geographical and economic regions of Nepal. The study can be linked towards the patients having diabetis mellitus and hyperuricemia in future $[29,30]$.

\section{Conclusion}

In this study among the hyperuricemic patients done in Nepal, mutation was found to be linked. Of the total sample, $40 \%$ were tested positive for rs2231142 mutation. They had both homozygous and heterozygous type of mutation. Among the mutated population sample, $75 \%$ had heterozygous mutation and remaining $25 \%$ had homozygous mutation. In general, $10 \%$ i.e 3 patients had homozygous mutation while $30 \%$ i.e 9 patients had heterozygous mutation and the rest $60 \%$ i.e 18 were found to be homozygous wild type. So, this study suggested heterozygous mutation was predominantly found in the sample population and there seems to be a greater chance of the linkage between the gene under study and uric acid patients.

This project was done in small scale, and small sample size with very limited budget and resources within the limited time frame. So, it may have got limitations regarding feasibility of the results. Expansion of this project to higher scale, however, with full supplementation of resources like sophisticated sequencing tools and larger number of samples providing enough fund needed for the completion of the research can provide better results.

\section{Limitation of the study}

30 samples were studied so far, all from hyperuricemic patients. The research was limited by the time and other constraints such as finance so only representational sample were collected. However, these limitations were minimized as far as possible.

\section{Acknowledgement}

The authors of this research would like to express sincere gratitude to DGRC and the whole team for providing the research facilities and necessary guidelines, and Nobel College for providing funding to make this work happen.

\section{References}

1. Dehghan A, Köttgen A, Yang Q Hwang SJ, Kao WL, (2008) Association of three genetic loci with uric acid concentration and risk of gout: a genome-wide association study. Lancet 372(9654): 1953-1961.

2. Waring WS, Webb DJ, Maxwell SRJ (2000) Uric acid as a risk factor for cardiovascular disease. QJM 93(11): 707-713.

3. Sivakumar K, Thamarai R, Jey Pragatha R (2014) Uric acid: A marker of increased various diseases and risks. Pharmacophore 5 (1): 35-43.

4. Yadav SK, Nepal N, Niroula DR (2015) Prevalence of Hyperuricemia among people of Morang district of Nepal. J Nobel Medical College 3(1).

5. Singh JA, Reddy SG, Kundukulam J (2011) Risk Factors of Gout and Prevention: A Systemic Review of the Literature. Curr Opin Rheumatol 23(2): 192202.

6. Stiburkova B, Pavlikova M, SokolovaKozichJ V (2014) Metabolic Syndrome, Alcohol Consumption and Genetic Factors Are Associated with Serum Uric Acid Concentration. PLoS ONE 9(5).

7. Feig DI, Kang DH, Johnson RJ (2008) Uric acid and cardiovascular risk. N Engl J Med 359: 1811-1821.

8. Ford ES, Li C, Cook S, Choi HK (2007) Serum concentrations of uric acid and the metabolic syndrome among US children and adolescents. Circulation 115(19): 2526-2532.

9. Fumihiko Takeuchi, Ken Yamamoto, Isono $\mathrm{M}$, Katsuya T, Akiyama K, et al. (2013) Genetic Impact on Uric Acid Concentration and Hyperuricemia in the Japanese Population. J Atheroscler Thromb 20(4): 351-367.

10. Cheng ST, Wu S, Su CW, Teng MS, Hsu LA, et al. (2017) Association of ABCG2 rs2231142-A allele and serum uric acid levels in male and obese individuals in a Han Taiwanese. J Formos Med Assoc 116(1): 18-23.

11. Sull JW, Yang SJ, Kim S, Jee SH (2014) The ABCG2 Polymorphism rs2725220 is Associated with Hyperuricemia in the Korean Population. Genomics Inf 12(4): 231-235.

12. Kolz M, Johnson T, Sanna S, Teumer A, Vitart V, et al. (2009) Meta-analysis of 28,141 individuals identifies common variants within five new loci that influence uric acid concentrations. PLoS Genet 5(6). 


\section{International Journal of Biochemistry \& Physiology}

13. Zhang L, Spencer KL, Voruganti VS, Jorgensen NW, Fornage M, et al. (2013) Association of functional polymorphism rs2231142 (Q141K) in the ABCG2 gene with serum uric acid and gout in 4 US populations. Am J Epidemiol 177(9): 923-932.

14. Anita Brandstätter, Claudia Lamina, Stefan Kiechl, Hunt SC, Coassin S, et al. (2010) Sex and age interaction with genetic association of artherogenic uric acid concentrations. Atherosclerosis 210(2): 474-478.

15. Woodward OM, Tukaye DN, Cui J, Cui J, Greenwell P, Constantoulakis LM, et al. (2013) Gout-causing Q141K mutation in ABCG2 leads to instability of the nucleotide-binding domain and can be corrected with small molecules. Proc Natl Acad Sci U S A 110(13): 5223-5228.

16. Dong Z, Guo S, Yang Y, Wu J, Guan M, et al. (2015) Association between ABCG2 Q141K polymorphism and gout risk affected by ethnicity and gender: A systematic review and meta-analysis. Int J Rheum Dis 18(4): 382-391.

17. Smith E, March L (2015) Global Prevalence of Hyperuricemia: A Systematic Review of PopulationBased Epidemiological Studies. Arthritis Rheumatol 67 (suppl 10).

18. S Kumar, AR Singh, R Takhelmayum, P Shrestha, JN Sinh (2010) Prevalence of hyperuricemia in Chitwan District of Nepal. J College Medical Sciences-Nepal 6(2): 18-23.

19. Neupane $Y$, Padmavathi $P$, Dubey RK, Gautam N, Jayan A, Sinha AK (2014) A hospital based retrospective study on prevalence of hyperuricemia in Lumbini zone, Nepal. Annals of Biological Research 5 (2): 8-11.

20. Li R, Miao L, Qin L, Xiang Y, Zhang X, et al. (2015) A meta-analysis of the associations between the Q141K and Q126X ABCG2 gene variants and gout risk. Int Clin Exp Pathol 8(9): 9812-9823.

21. Yamagishi K, Tanigawa T, Kitamura A, Köttgen A, Folsom AR, et al. (2010) The rs2231142 variant of the ABCG2 gene is associated with uric acid levels and gout among Japanese people. Rheumatology 49(8): 1461-1465.
22. Kim YS, Kim Y, Park G, Kim SK, Choe JY, et al. (2015) Genetic analysis of ABCG2 and SLC2A9 gene polymorphisms in gouty arthritis in a Korean population. Korean J Intern Med 30(6): 913-920.

23. Zhou D, Liu Y, Zhang X, Gu X, Wang H, et al. (2014) Functional polymorphisms of the ABCG2 gene are associated with gout disease in the Chinese Han male population. Int J Mol Sci 15(5): 9149-9159.

24. Stark K, Reinhard W, Grassl M, Jeanette Erdmann, Heribert Schunkert, et al. (2009) Common polymorphisms influencing serum uric acid levels contribute to susceptibility to gout, but not to coronary artery disease. PLoS One 4(11).

25. Phipps-Green AJ,Hollis-Moffatt JE, Dalbeth $\mathrm{N}$, Merriman ME, Topless R, et al. (2010) A strong role for the ABCG2 gene in Susceptibility to gout in New Zealand Pacific Island and Caucasain but not Maori, case and control sample sets. Hum Mol Genet 19(24): 4813-4819.

26. Zheng C, Yang H, Wang Q, Rao H, Diao Y (2016) Association analysis of five SNP variants with gout in the Minnan population in China. Turkish J Med Sci 46(2): 361-367.

27. Takeuchi $F$, Yamamoto $K$, Isono $M$, Katsuya $T$, Akiyama K, et al. (2013) Genetic impact on uric acid concentration and hyperuricemia in the Japanese population. J Atheroscler Thromb 20(4): 351-367.

28. Yang B, Mo Z, Wu C, Yang H, Yang X, et al. (2014) A genome-wide association study identifies common variants influencing serum uric acid concentrations in a Chinese population. Bio Med Central Med genomics. 7(1): 10 .

29. Rajbhandari PMS, Gyawali P, Mahato RV, Chaudhary D, Koirala N, et al. (2017) A cross-sectional prospective study of glycated hemoglobin (Hba1c) and fasting blood glucose (Fbg) level in both diabetic and non-diabetic patients in context to nepalese general population. M J Diab 2(2): 007.

30. Adhikari S, Shrestha S, Shakya R and Koirala N (2017) Prevalance of chronic complications and drug utilization pattern of type II diabetes mellitus. M J Diab 1(1): 006. 